\title{
Erratum to: Effects of dietary protease on immune responses of weaned pigs
}

Jeong Jae Lee ${ }^{1 \#}$, Joowon Kang ${ }^{1 \#}$, Sangwoo Park ${ }^{1 \#}$, Jin Ho Cho ${ }^{2 \#}$, Sejong $\mathrm{Oh}^{3}$, Dong-Jun Park ${ }^{4}$, Rider Perez-Maldonado ${ }^{5}$, Jee-Yeon $\mathrm{Cho}^{6}$, II-Hun Park ${ }^{6}$, Hyeun Bum Kim ${ }^{7 *}$ and Minho Song ${ }^{1 *}$

${ }^{1}$ Division of Animal and Dairy Science, Chungnam National University, Daejeon 34134, Korea

${ }^{2}$ Division of Food and Animal Science, Chungbuk National University, Cheongju 28644, Korea

${ }^{3}$ Department of Animal Science, Chonnam National University, Gwangju 61186, Korea

${ }^{4}$ Korea Food Research Institute, Wanju 55365, Korea

${ }^{5}$ DSM Nutritional Products Asia Pacific, Mapletree Business City 117440, Singapore

${ }^{6}$ DSM Nutrition Korea Ltd., Seoul 06675, Korea

${ }^{7}$ Department of Animal Resources Science, Dankook University, Cheonan 31116, Korea

\section{ERRATUM}

In the published article "Effects of dietary protease on immune responses of weaned pigs. J Anim Sci Technol 2020;62(2):174-9. https://doi.org/10.5187/jast.2020.62.2.174,”TGF- $\alpha$ should be modified to TNF- $\alpha$ on the y-axis of Fig. 2 [1]. The editorial office would like to correct it.

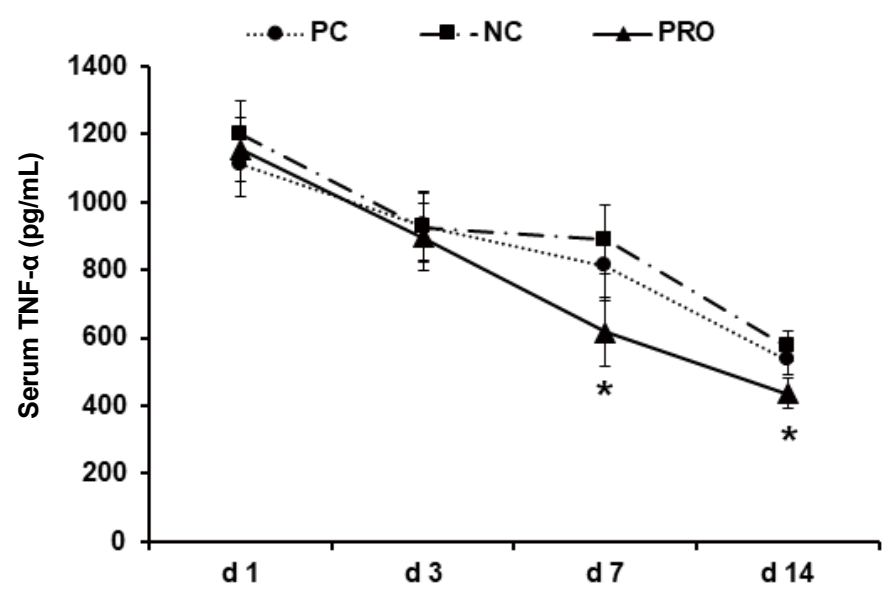

Fig. 2. Effect of dietary protease on serum TNF- $\alpha$ of weaned pigs. Each value is the mean of 5 replicates. ${ }^{*}$ Difference between PRO and NC $(p<0.10)$. PC, positive control; NC, negative control; PRO, negative control + $0.02 \%$ dietary protease. 


\section{Sejong Oh}

https://orcid.org/0000-0002-5870-3038

Dong-Jun Park

https://orcid.org/0000-0001-9452-9391

Rider Perez-Maldonado

https://orcid.org/0000-0001-7695-5258

Jee-Yeon Cho

https://orcid.org/0000-0002-7067-1841

II-Hun Park

https://orcid.org/0000-0003-0851-4180

Hyeun Bum Kim

https://orcid.org/0000-0003-1366-6090

Minho Song

https://orcid.org/0000-0002-4515-5212

\section{REFERENCES}

1. Lee JJ, Kang J, Park S, Cho JH, Oh S, Park DJ, Perez-Maldonado R, Cho JY, Park IH, Kim HB, Song M. Effects of dietary protease on immune responses of weaned pigs. J Anim Sci Technol 2020;62(2):174-9. 